\title{
Splenic rupture visualised with focused assessment with sonography for trauma (FAST): heterogeneous echogenicity of acute haemorrhage following blunt trauma
}

\author{
Gerard O’Connor, Vinesh Ramiah, John Mclnerney, Adrian Moughty \\ Department of Emergency Medicine, Mater Misericordiae University Hospital, Dublin, Ireland
}

Correspondence to Dr Gerard O'Connor, geroconnor@me.com

\section{DESCRIPTION}

Focused assessment with sonography in trauma (FAST) is now widely recognised as a mainstream emergency medicine technique in the management of trauma. The conventional areas that are screened for intraperitoneal blood following trauma include the hepatorenal interface (Morison's pouch), perisplenic space, pericardium and the pelvis. In the context of abdominal trauma, fluid or blood is indicated by the presence of black anechoic collections. The utility of FAST in solid organ evaluation is less clear. Historically, EM physicians have avoided (non-binary) qualitative comments on organ structure or disruption.

We report a case where FAST resulted in early diagnosis of splenic rupture, allowing for early institution of prophylactic anti-opportunistic postsplenectomy infection measures and urgent CT.

A gentleman in his 30 s presented with blunt trauma to left lateral chest and abdomen. This occurred as a result of being thrown from a motorcycle in a motor-vehicle accident. On presentation, his haemodynamic vital signs were within normal parameters. He exhibited tenderness over the left anterolateral torso.

FAST revealed heterogeneous echogenicity of the spleen consistent with splenic haemorrhage (figures 1 and 2). CT

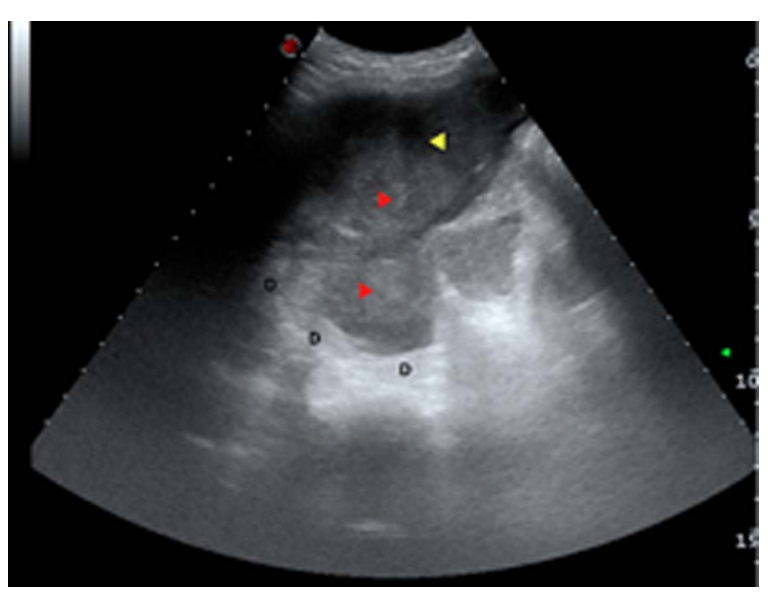

Figure 1 Heterogeneous echogenicity of acute haemorrhage. Red arrowheads shows hyperechoic areas and yellow arrowhead indicates hypoechoic areas. The curvilinear diaphragm is indicated by $\mathrm{D}$.

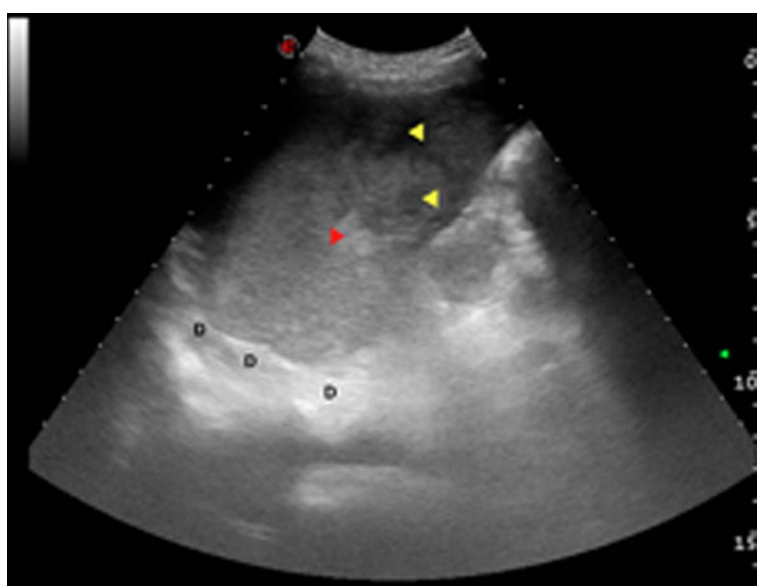

Figure 2 Heterogeneous echogenicity of splenic injury. Red arrowhead indicates hyperechoic area and yellow arrowheads indicate hypoechoic areas. Diaphragm is indicated by $D$.

confirmed ruptured spleen (figure 3) and the patient proceeded to laparotomy.

Splenic injury without sonographic haemoperitoneum has been frequently described and can occur in up to $29 \%$ ${ }^{1-3}$ of cases. As emergency physicians' proficiency in FAST becomes more refined, the subtle architectural and echogenic changes with various pathologies become more apparent. FAST practitioners should be aware of these (sometimes subtle) signs that have the potential to significantly alter and improve patient management.

\section{Learning points}

Splenic injury without sonographic haemoperitoneum occurs in up to $29 \%$ of cases.

- Normal splenic architecture exhibits homogeneous echogenicity on ultrasound.

- Splenic heterogeneous echogenicity on FAST examination should suggest the possibility of severe splenic disruption. 


\section{BMJ Case Reports}

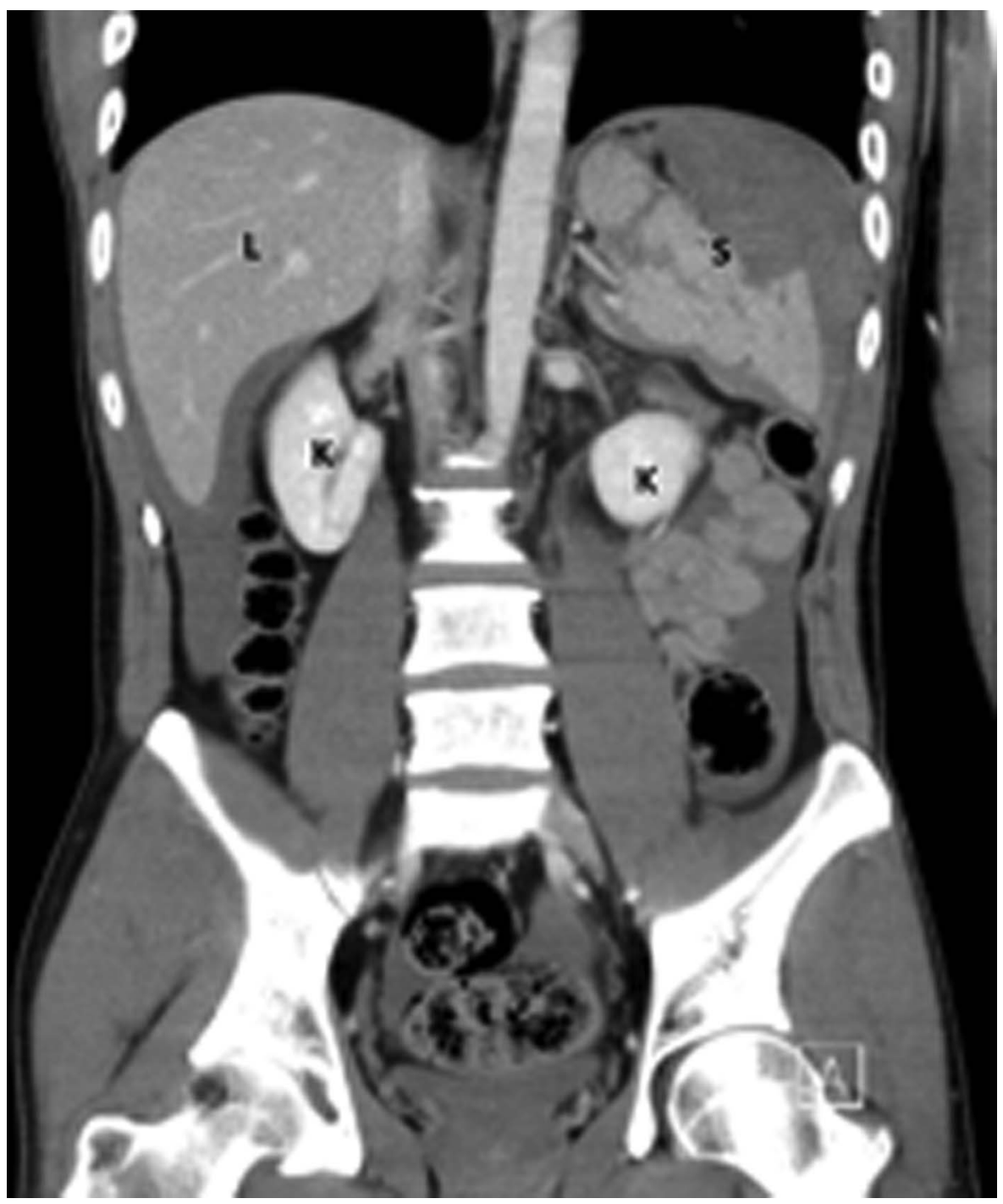

Figure 3 Coronal CT of splenic trauma. L, liver; S, spleen; K, kidney.

\section{Competing interests None.}

Patient consent Obtained.

\section{REFERENCES}

1. Boscak A, Shanmuganathan K. Splenic trauma: what is new? Radiol Clin North Am (Review) 2012;50:105-22.
2. Shanmuganathan K, Mirvis SE, Sherbourne CD, et al. Hemoperitoneum as the sole indicator of abdominal visceral injuries: a potential limitation of screening abdominal US for trauma. Radiology 1999;212. 423-30.

3. Chiu WC, Cushing BM, Rodriguez $A$, et al. Abdominal injuries without hemoperitoneum: a potential limitation of focused abdominal sonography for trauma (FAST). J Trauma 1997;42:617-23; discussion 23-5. 


\section{BMJ Case Reports}

Copyright 2012 BMJ Publishing Group. All rights reserved. For permission to reuse any of this content visit http://group.bmj.com/group/rights-licensing/permissions.

BMJ Case Report Fellows may re-use this article for personal use and teaching without any further permission.

Please cite this article as follows (you will need to access the article online to obtain the date of publication).

O'Connor G, Ramiah V, Mclnerney J, Moughty A. Splenic rupture visualised with focused assessment with sonography for trauma (FAST): heterogeneous echogenicity of acute haemorrhage following blunt trauma. BMJ Case Reports 2012;10.1136/bcr-2012-007336, Published XXX

Become a Fellow of BMJ Case Reports today and you can:

- Submit as many cases as you like

- Enjoy fast sympathetic peer review and rapid publication of accepted articles

Access all the published articles

- Re-use any of the published material for personal use and teaching without further permission

For information on Institutional Fellowships contact consortiasales@bmjgroup.com

Visit casereports.bmj.com for more articles like this and to become a Fellow 